\title{
USO E OCUPAÇÃO DO SOLO: REFLEXÃO SOBRE IMPACTO AMBIENTAL
}

\author{
Paulo Sergio dos Santos ${ }^{1}$, Marcia Eliza de Godoi dos Santos², Raul dos Santos ${ }^{3}$
}

\section{RESUMO:}

O desenvolvimento urbano no Brasil, assim como em grande parte dos países subdesenvolvidos, ocorreu de forma negligente com os recursos naturais. Analisar o contexto ambiental nos permite destacar problemas, viabilizando a identificação de focos de degradação ambiental instalados e o grau de comprometimento local. O objetivo deste artigo foi analisar as produções cientificas sobre a temática recorrente de infiltração nas bacias hidrográficas e contextualizar o uso consciente e sustentável do solo. O estudo apresenta uma abordagem qualitativa e resultou de uma revisão bibliométrica de forma sistemática na biblioteca online, em originais publicados no período de 2015 a 2020 indexados na base de dados da Scielo e CAPES. Procurou-se identificar as produções científicas que fazem menção ao uso e ocupação do solo. Os resultados da pesquisa demonstram a necessidade do gerenciamento dos recursos hídricos e o acompanhamento nas alterações no uso e na ocupação do solo, para estrategicamente proteger e restaurar a qualidade ambiental, visto que o empobrecimento do solo poderá agravar a situação de toda extensão da bacia, gerando consideráveis impactos no curso d'água. Vários autores chamam a atenção para inúmeros casos de exploração de recursos naturais, extensão de áreas frágeis nas bacias, movimento de massas e inundações. Diante disso, a abordagem aqui adotada procura integrar os aspectos ambientais, econômicos e sociais e destaca a importância da conscientização sustentável ambiental. Os estudos mostraram que devido a existência de lacunas, há diversas oportunidades de pesquisa a serem aprofundadas sobre o tema, visando um processo de conscientização sustentável para o desenvolvimento de uma sociedade promissora.

Palavras-chave: bacias hidrográficas, manejo do solo, recursos naturais.

\section{LAND USE AND OCCUPATION: REFLECTION ON ENVIRONMENTAL IMPACT}

\section{ABSTRACT:}

Urban development in Brazil, as in most underdeveloped countries, occurred negligently with natural resources. Analyzing the environmental context allows us to emphasize problems, enabling the identification of environmental degradation focus installed and the level of local commitment. The objective of this article was to analyze scientific productions on the recurrent theme of infiltration in hydrographic basins and to contextualize the conscious and sustainable use of the soil. The study presents a qualitative approach resulting from a systematic review of literature in the online library, in originals published from 2015 to 2020 indexed in the database of Scielo and CAPES. An attempt was made to identify scientific productions that mention land use and occupation. The results of the research demonstrate the need for water resources management and monitoring changes in landuse and occupation to strategically protect and restore environmental quality,

\footnotetext{
1 Mestre em Ciências Ambientais da Universidade de Taubaté, e-mail: engpaulosantos18@gmail.com.

2 Mestra em Gestão e Desenvolvimento Regional pela Universidade de Taubaté, e-mail: marciae.godoisantos@gmail.com.

${ }^{3}$ Bacharel em Engenharia Civil da Universidade de Taubaté, e-mail: raul@pssaengenharia.com.br
} 
ISSN 2525-4804

since the impoverishment of the soil may aggravate the situation of the entire extension of the basin, generating considerable impacts on the water course. Several authors call attention to countless cases of exploitation of natural resources, extension of fragile areas in the basins, mass movement and floods. In this sense, the approach adopted here seeks to integrate environmental, economic and social aspects and emphasize the importance of sustainable environmental awareness. Studies have shown that, due to the existence of gaps, there are several research opportunities to be developed on this topic, aiming at a sustainable awareness process for the development of a promising society.

Keywords: Hydrographic basins, soil management, natural resources. 


\section{INTRODUÇÃO}

O crescimento urbano desordenado e desigual nas cidades brasileiras tem acarretado, em muitos casos, uma série de problemas que impactam no desenvolvimento funcional urbano e no uso e ocupação do espaço (Silva, 2015, p.2).

Segundo Silva (2015), as cidades brasileiras não estavam preparadas para um crescimento populacional tão rápido, por isso, acumularam, a partir de então, problemas de todas as ordens, o que ocasionou uma distribuição desigual de recursos naturais.

A ocupação espacial tem crescido em grande escala, decorrente da demanda do modelo econômico homogêneo contemporâneo, porém na mesma escala cresce o esgotamento dos recursos naturais, tornando o padrão de desenvolvimento baseado na sustentabilidade um fator quase ilusório, principalmente com relação aos recursos naturais renováveis (Santos, 2005).

Todavia, diante dessa compreensão dos recursos naturais, Santos et al. (2020a) aponta para urgência de gerenciamento dos recursos hídricos e para acompanhamento no uso e na utilização do solo das margens dos rios e bacias hidrográficas, afim de proteger e restaurar as características naturais da terra.

De acordo com Targa (2011), as ações antrópicas negativas e uso inadequado do solo ocasionam problemas ambientais, provocam a rápida sedimentação e assoreamento dos leitos, levando à redução na quantidade e qualidade das águas, sendo necessário caminhar para consciência ambiental sustentável.

Para Santana e Araújo (2017), o solo é um recurso natural de alta importância social, econômica e ambiental. As práticas inadequadas de ocupação do solo são responsáveis em grande parte pelo processo de degradação, contribuindo para perda de solo e baixa produtividade. Os autores destacam que a erosão resulta da ação do impacto de chuva e da enxurrada sobre o solo. Esses acontecimentos transportam os nutrientes, a matéria orgânica e os defensivos agrícolas, causando prejuízo principalmente, para as atividades agrícolas.

Para Costa (2010), é urgente uma tomada de consciência quanto aos problemas resultantes do modelo agrícola atual e de técnicas rudimentares. Isso se faz necessário para que se consiga conciliar um sistema produtivo que conserve os recursos naturais e forneça produtos para sustento da humanidade.

Segundo Nunes e Roig (2015), o mal-uso e ocupação inadequada do solo pode arruinar a integridade das bacias hidrográficas. Na agricultura, as áreas com preparo de solo inadequado, resultam na erosão, assoreamento de rios e contaminação das águas, por uso excessivo de fertilizantes e agrotóxicos. Essa atitude deixa sequelas ambiental, conduz a um processo de lixiviação e ação antrópica, provocando grandes alterações no meio ambiente.

De acordo com Santos et al. (2020b), o gerenciar de recursos hídricos está contido em um contexto de discussão e reflexão mais abrangente, esse processo deve ser resultado histórico de crescimento e desenvolvimento humano. O gerenciamento dos recursos visa envolver as bacias hidrográficas como um todo, ou seja, sob a estratégia de proteger e restaurar a riqueza ambiental local. Para os autores, trata-se, portanto, de uma visão concreta de desenvolvimento sustentável, do uso de recursos naturais e de ocupação do ecossistema, respeitando os limites, atentando-se para preservação, correção e mitigação de prováveis impactos ambientais indesejáveis.

Dessa forma, este estudo tem como objetivo geral analisar as produções científicas sobre a temática recorrente de infiltração nas encostas dos rios e contextualizar o uso consciente e sustentável do solo, e, como objetivos específicos, identificar as produções científicas que fazem menção ao Uso do Solo e Bacia Hidrográfica e analisar ações negativas quanto a ocupação inadequada do solo.

As ações negativas quanto a ocupação inadequada do solo, segundo Nunes e Roig (2015), 
podem levar a alterações do escoamento superficial e, consequentemente, do ciclo hidrológico, a feições erosivas, a contaminação superficiais e subterrâneas, ocasionando o desequilíbrio do ecossistema da região. Portanto, o monitoramento e a análise do uso e ocupação do solo são imprescindíveis na prevenção desses impactos e na manutenção dos mananciais.

Segundo Santos et al. (2020b), a discussão sobre consumo sustentável que aflora no contexto contemporâneo se apresenta pela necessidade do desenvolvimento relacionado ao avanço econômico, social e ecológico e pelo uso consciente dos recursos da natureza.

As transformações sociais, políticas e ambientais, ocasionadas pelo avanço tecnológico e científico, resulta na exploração inadequada no meio ambiente, muitas vezes consequência da ação imprudente do homem. O processo de degradação do solo acontece por vários motivos, os quais resultam em danos à natureza e ao impacto negativo dos espaços (Santos, 2019).

Um dos grandes desafios do homem sobre a conservação do meio ambiente está em concentrar esforços e recursos para preservar e recuperar as áreas naturais (Sartori et al., 2009).

Para Araújo et al. (2010), a atividade humana inconsequente acelera o processo de desgaste e perda do solo. As queimadas e o desmatamento, por exemplo, são fatores que contribuem e causam a erosão, as quais estão associadas ao desgaste do solo a partir de práticas agrícolas sem manejo adequado do solo, e por meio de culturas e cultivo não adaptados às características dos solos.

A camada vegetal é essencial porque promove o equilíbrio entre o solo e o meio físico. A infiltração da água é um indicador de diferença no comportamento hidrodinâmico do solo; já as ações antrópicas, como as pastagens, em coberturas naturais vegetais, provocam profundas alterações e transformações no solo. De modo geral, as modificações que ocorrem nas bacias hidrográficas interferem de modo direto no escoamento superficial das águas, muitas vezes, dificultando ou impedindo sua infiltração, ocasionando as enchentes e alagamentos (Araújo, et al., 2010).

Segundo Santana e Araújo (2017), a vegetação, independentemente do tamanho, tem raízes que fazem ancoragem do solo. Isso significa que as árvores agem como "guarda-chuvas" do solo, e a vegetação age como um redutor de velocidade das águas que correm no solo.

Para Costa (2010), é fundamental o solo ter uma boa cobertura vegetal, pois isso é indispensável para que haja um filtro, e para que as águas não escorram em forma de enxurrada, ocasionando infiltração excessiva e chegando em abundância às partes mais baixa do solo, podendo contaminar as minas d'água.

"Os riscos de erosão dependem tanto das condições naturais quanto dos modelos de uso da terra" (Araújo et al., 2010, p.24).

\section{MATERIAL E MÉTODOS}

Esta pesquisa caracteriza-se como um estudo descritivo exploratório de caráter qualitativo.

$\mathrm{O}$ estudo teve início com um levantamento bibliográfico, o que possibilitou a realização de uma pesquisa bibliométrica sobre estudo dos solos, suas propriedades e o processo erosivo do solo resultante da má utilização pela sociedade.

Optou-se pela investigação bibliométrica por se tratar de um método planejado, que possibilita coletar, selecionar, analisar de modo crítico os estudos.

Segundo Rother (2007), a pesquisa bibliográfica possibilita o estudo de artigos nos quais possamos realizar análises e interpretações críticas, possibilitando compreender o "estado da arte" de um determinado assunto, sob um ponto de vista teórico ou contextual. Nesse sentido, a construção textual perpassa por etapas de um processo de construção metodológica que se empenha em elaborar um escrito cientificamente coerente com suas referências e contextos (Metring, 2009).

Como estratégia para pesquisa, utilizou-se uma sequência de passos: 
$1^{\circ}$ passo: escolha do banco de dados - Optou-se pela pesquisa online, na base de dados Scientific Electronic Library (SCIELO) e na base de dados da Coordenação de Aperfeiçoamento de Pessoal de Nível Superior (CAPES). Através desses bancos de dados realizou-se uma pesquisa Bibliométrica. A escolha dessas bases de dados deu-se por sua confiabilidade e reconhecimento no meio acadêmico, sendo referência na busca de materiais de qualidade para a construção de fundamentações teóricas e afins.

Foi delimitado o objeto de estudo, e posteriormente feito a pesquisa exploratória, cuja finalidade foi obter uma maior aproximação do tema por meio de leitura de artigos. $\mathrm{Na}$ análise das produções foram avaliados conceitos referentes ao uso e ocupação do solo. As palavras-chave utilizadas para a realização da pesquisa foram: uso e ocupação do solo e, refinando a pesquisa utilizou-se o descritor: infiltração de água. $\mathbf{2}^{\mathbf{0}}$ passo: iniciou-se com o registro da pesquisa num âmbito ampliado, na tentativa de compreender o universo da temática estudada e a forma sistematizada dos estudos publicados de 2015 a 2020.

Os critérios básicos de filtros (descritas no quadro 1), indexadas nas bases de dados da SCIELO e CAPES, permitiram dar início a pesquisa.

Procedeu-se com a execução de buscas nas plataformas, com os critérios apontados no Quadro1. $\mathrm{O}$ total dos artigos gerados, no primeiro momento, com apenas um descritor, foi considerado para análise bibliométrica, sem nenhuma exclusão. Acrescentouse então, um novo corte na revisão bibliométrica, um novo descritor, com o objetivo de aproximar os estudos ao objeto, foco da pesquisa.

Quadro 1 - Pesquisa na base de dados Scielo e CAPES

\begin{tabular}{cc}
\hline \multicolumn{2}{c}{ Pesquisa na Base de Dados Scielo e Capes } \\
\hline Critérios & Descritores \\
\hline Palavra-chave & Uso do Solo \\
Inserção de nova palavra-chave & Infiltração de água \\
Delimitação temporal & 2015 a 2020 \\
Delimitação por categoria de estudos & Artigos \\
\hline
\end{tabular}

$3^{\circ}$ passo: Deu-se continuidade aos estudos com a leitura dos títulos e resumos. Os artigos foram excluídos por não responderem à pergunta norteadora e motivadora do estudo: Diante dos desafios da sociedade contemporânea que diretrizes e pressupostos devem guiar o uso consciente e sustentável do solo?

Criteriosamente, foram excluídas as produções em duplicidade, monografias, dissertações e teses. Segue na Tabela 1 a relação dos números de produções e resultados da pesquisa.

Quanto a análise dos periódicos (apenas artigos completos), a intenção foi de explorar os 05 artigos selecionados que mais se assemelhavam com o tema.
Como critério de análise, tem-se: Objetivo da pesquisa, tipo de pesquisa nível de análise (individual ou em grupo); método de pesquisa (qualitativa, quantitativa); contexto da pesquisa e análise conclusiva dos autores.

O intuito desta fase consistiu em destacar os conhecimentos dos pesquisadores sobre o universo dos estudos a respeito do uso e ocupação do solo. Nesse sentido, buscou-se identificar indicadores sobre a temática e questionamentos quanto ao uso e ocupação do solo e uso consciente dos recursos naturais, considerando o contexto social contemporâneo. 
Tabela 1. Dados relacionados ao número de produções

Produções de 2015 a 2020

\section{Descritores \\ Uso e ocupação do solo/ \\ Infiltração de água}

Banco de dados

\section{Artigo selecionados para estudo}

$\begin{array}{ccc}\text { SCIELO } & 20 & 03 \\ \text { CAPES } & 44 & 02\end{array}$

Fonte: Dados da pesquisa

\section{RESULTADOS E DISCUSSÕES}

Através dos materiais procurados nas bases de dados citadas, foram selecionados 05 artigos que contribuíram na produção deste trabalho. A primeira leitura foi seguida de fichamento dos textos a fim de compor as ideias de estrutura do trabalho. Os dados estão no quadro abaixo especificando: título; autor do texto; ano de publicação e fonte (Tabela2).

Em grande parte da literatura consultada pode-se observar a necessidade da ênfase aos benefícios das práticas de conservação do solo.
Também foi possível observar, a preocupação dos autores em destacar a relevância de promover uma discussão acerca da gestão para conservação do solo, principalmente de estabelecer políticas públicas voltadas à preservação do meio ambiente e das riquezas naturais.

Guerra et al. (2014) destaca a notoriedade das ações preventivas, e salienta quanto a vulnerabilidade dos solos brasileiros à erosão hídrica, sendo este elencado como o principal fator de esgotamento da capacidade produtiva dos solos brasileiros.

Tabela 2. Artigos selecionados.

\begin{tabular}{|c|c|c|c|}
\hline Título & Autor & Ano & Fonte \\
\hline Efeitos de Cenários de Uso do Solo sobre o regime & Perazzoli, M.; & 2013 & Scielo \\
\hline Hídrico e Produção de sedimentos na Bacia do & Pinheiro, A.; & & \\
\hline Ribeirão Concórdia - SC & Kaufmann, V. & & \\
\hline $\begin{array}{l}\text { Análise e Mapeamento do Uso e Ocupação do Solo } \\
\text { da Bacia do Alto do Descoberto, DF/Go, por meio de } \\
\text { classificação automática baseada em regras e lógica } \\
\text { nebulosa }\end{array}$ & $\begin{array}{l}\text { Nunes, J F.; Roig, H. } \\
\text { L. }\end{array}$ & 2015 & Scielo \\
\hline $\begin{array}{l}\text { O Uso da Terra e dos Recursos Hídricos da Bacia do } \\
\text { córrego Facão, Pantanal de Cáceres, Mato Grosso }\end{array}$ & $\begin{array}{l}\text { Cruz, J.S.; Souza, C. } \\
\text { A.; William, C. S.; } \\
\text { Silva, V. N. }\end{array}$ & 2017 & CAPES \\
\hline $\begin{array}{l}\text { Relações entre qualidade da água subterrânea e } \\
\text { ocupação desordenada em um bairro be baixa renda } \\
\text { localizado em uma antiga área de lixão, Santarém/PA }\end{array}$ & $\begin{array}{l}\text { Galvão, P.; Mendes, } \\
\text { A.; Sousa, J.; Silva, I.; } \\
\text { Carneiro, R. }\end{array}$ & 2019 & CAPES \\
\hline $\begin{array}{l}\text { Caracterização Ambiental do uso e ocupação do solo } \\
\text { das áreas de influência em municípios da rota de } \\
\text { Integração Latino-Americana. }\end{array}$ & $\begin{array}{l}\text { Pereira, M.A.S.; } \\
\text { Magalhães Filho, } \\
\text { F.J.C.; Teles, A.P.S.; } \\
\text { Ayres, F.M. }\end{array}$ & 2019 & Scielo \\
\hline
\end{tabular}


Pinheiro et al. (2011), em seus estudos, ressalta que o uso e ocupação inadequada dos solos agrícolas vem acentuando a perda gradual da sua capacidade produtiva e a degradação de recursos hídricos por elementos sedimentados e poluentes. Isso ocorre porque o uso do solo pode afetar os processos hidrológicos do solo na bacia.

A ação antrópica tem acelerado esses processos de modo intenso, ocasionando prejuízos ao setor agrícola e ao meio ambiente e com reflexos econômicos e sociais.

Segundo Perazzoli et al. (2013), o tipo de uso e ocupação e cobertura do solo, interfere nos processos hidrológicos, e consequentemente no regime de vazões e na produção de sedimentos em uma caia hidrográfica. Em curto prazo, grandes alterações do solo acarretam maiores impactos no regime e na disponibilidade hídrica da bacia.

Para Nunes et al. (2015), a impermeabilização do solo através da expansão urbana pode afetar a percolação das águas fluviais e o regime hídrico. $\mathrm{O}$ uso e cobertura do solo têm vários impactos no ciclo hidrológico, tais como, inundações, secas, escoamento e a qualidade da água.

Segundo Pruski et al (2001), a degradação do solo e o assoreamento dos cursos e reservatórios naturais de água são preocupação de toda sociedade. Nesse sentido, torna-se urgente o entendimento de processos que envolvem a proteção e preservação do solo, uma vez que a erosão hídrica está diretamente relacionada à precipitação e ao escoamento superficial do solo.

Para santos (2019), o processo de infiltração é bastante complexo, pois, mesmo o solo sendo homogêneo ocorre muitos eventos de precipitação. Existe um período inicial de infiltração de água no solo e, durante esse processo, a capacidade de infiltração decresce, fazendo com que essa água seja acumulada na superfície do solo, situação em que pode ocorrer o escoamento superficial.

Ribeiro et al. (2011), salientam que o escoamento começa após o armazenamento excessivo de água no solo. $\mathrm{O}$ autor ressalta que o escoamento superficial ocorre quando a intensidade da precipitação excede a velocidade de infiltração da água no solo. Nessa ocorrência, quando a velocidade de infiltração é excedida, a água preenche as depressões existentes na superfície do solo, resultando no escoamento superficial.

Os modelos de precipitação por escoamento possuem uma importante função no entendimento das condições hidrológicas das bacias. Cruz et al. (2017), Galvão et al. (2019) e Pereira et al. (2019) destacam a importância do monitoramento e ações de preservação. Segundos os autores, apesar de serem mais protegidas que as águas superficiais, as águas subterrâneas, principalmente aquelas em aquíferos rasos e em condições de não confinamento, podem ser alteradas quando determinados contaminantes infiltram nas zonas de recargas e alcançam o lençol freático. Dependendo do uso e ocupação do solo, bem como da forma, volume, tempo e natureza da disposição do resíduo em função de sua toxidade, a contaminação pode ser mais significativa e persistente no aquífero.

De acordo com Pereira et al. (2019), em virtude dos novos desafios econômicos e sociais, por muitas vezes as questões ambientais foram deixadas para segundo plano. Segundo os autores, o aprimoramento e o desenvolvimento de novas tecnologias e de novos instrumentos normativos, possibilitaram realização de análises mais especificas dos impactos na natureza, objetivando assim, o monitoramento e avaliação dos impactos causados ao meio ambiente.

As palavras em destaque na pesquisa (Figura 1): escoamento superficial, bacia hidrográfica, sustentável, infiltração, ciências ambientais, apontam para importância da discussão acerca dos cuidados, gerenciamento, manutenção e acompanhamento das bacias hidrográficas e dos recursos naturais: escoamento superficial, drenagem, uso e ocupação do solo. 


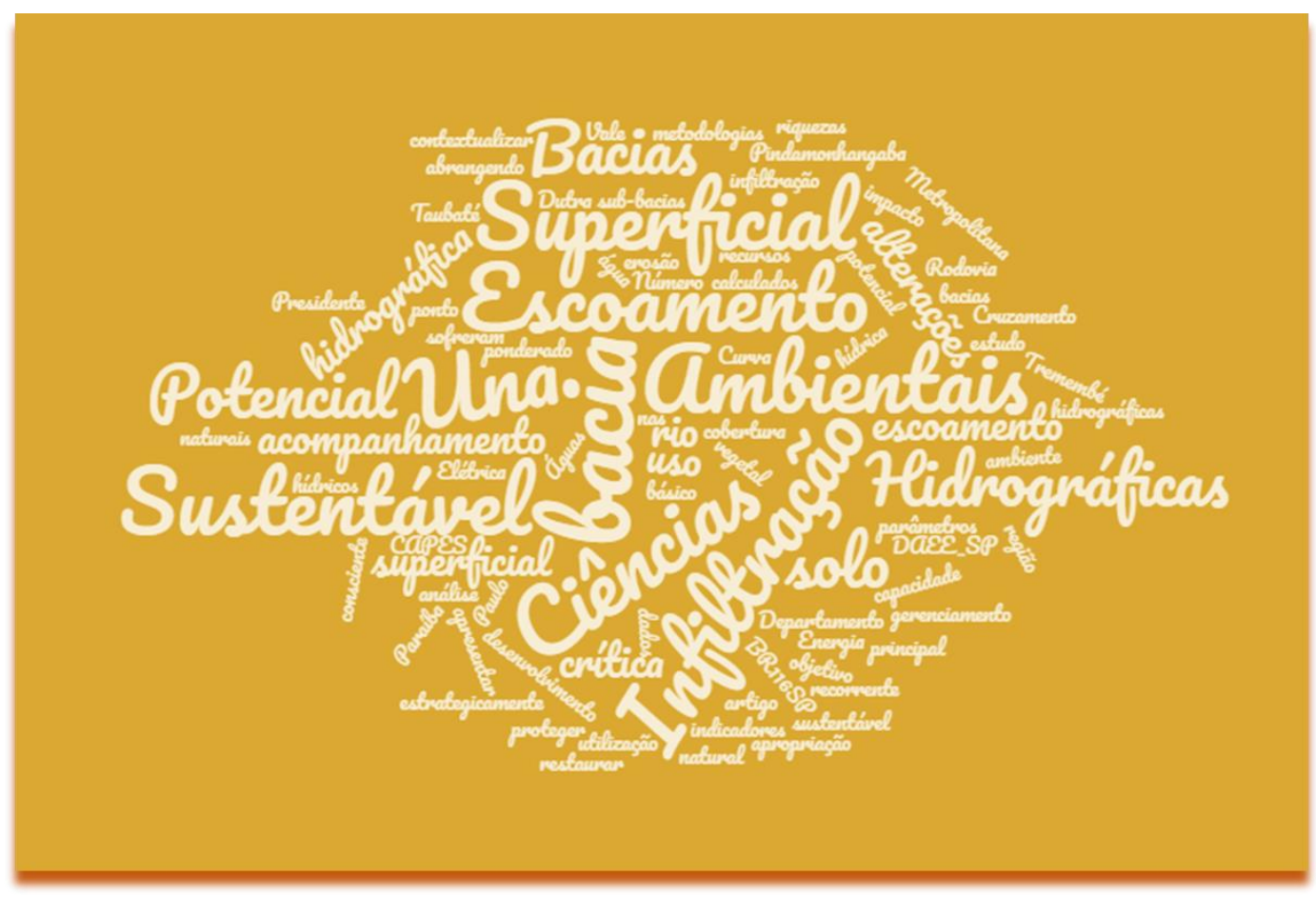

Figura 1. Wordcloud de palavras-chave dos documentos analisados na base de dados WoS. Fonte: Elaborado pelo autor, https://www.wordclouds.com/

Os descritores ressaltados na pesquisa alertam para estudos hídricos considerando a necessidade de atenção ao uso e ocupação das áreas ao entorno das bacias, e ainda, sublinha a importância de um novo e emergente olhar sobre os impactos ambientais: degradação ambiental e escorrimentos superficiais excessivos, que carreiam sedimentos que irão resultar no assoreamento do solo.

Para Santos (2019), esses fenômenos de degradação ambiental acontecem pela má utilização do solo, ou ainda, quando o solo é utilizado de modo a transgredir sua capacidade funcional, desconsiderando a dinâmica do meio físico. Esse processo resulta em impactos consideráveis ao ambiente, pois acabam ocasionando riscos prejudiciais a sociedade e provocando movimento de massas, enchentes, inundação e alagamentos.

Para Primavesi (2014), a reflexão sobre a importância do solo e do meio ambiente perpassa os conceitos de sustentabilidade no momento que se relaciona com recursos naturais e com a continuidade dos mesmos. Nesse sentido, o conceito de sustentabilidade, que baliza esse trabalho, segue os preceitos apontados por Boff (2015) que ela corresponde a uma linha mestra de sustentação do planeta e das espécies, referindo-se ao solo como ingrediente essencial para continuidade da vida.

\section{CONCLUSÃO}

Os resultados da pesquisa demonstram a necessidade do gerenciamento dos recursos hídricos e o acompanhamento nas alterações no uso e a ocupação do solo para proteger e restaurar a qualidade ambiental, posto que o empobrecimento do solo poderá agravar a situação de toda extensão da bacia hidrográfica.

Os estudos mostraram, ainda, que há lacunas e oportunidades de pesquisa a serem aprofundadas, visando o desenvolvimento saudável de uma sociedade promissora.

É evidente que o solo é um recurso essencial à vida; entretanto, é emergente sensibilizar toda sociedade para a importância de um manejo adequado 
quanto ao uso e ocupação do solo, visando a manutenção e cuidado de todas as suas funções.

Vários autores chamam a atenção para inúmeros casos de exploração de recursos naturais, extensão de áreas frágeis nas bacias, movimento de massas e inundações.

Portanto, diante do uso e ocupação do solo, a principal prática de conservação e preservação consiste na utilização do solo conforme sua capacidade de uso. Nesta perspectiva, torna-se indispensável a necessidade do reconhecimento de seu potencial, já que são de extrema importância para conservação dos mananciais hídricos e consequentemente para o equilíbrio ecossistêmico.

A discussão da consolidação de uma educação ambiental como mola propulsora para preservação de recursos naturais é essencial para que o processo de conscientização sustentável se efetive.

Fica evidente a responsabilidade de cada um no processo de conservação dos recursos naturais, com destaque para o uso e ocupação do solo, como condição de melhoria para o desenvolvimento de toda sociedade.

Nesse sentido, deve-se conduzir ações para uma real mudança de atitude frente aos recursos ambientais naturais. Isso indica que é fundamental o desenvolvimento de uma cultura de educação ambiental e de promoção adequada ao uso e manejo consciente do solo, visando o potencial de produção, sustentabilidade e impacto ambiental.

\section{REFERÊNCIAS BIBLIOGRÁFICAS}

Araújo, G. H.S.; Almeida, J.R.; Guerra, A. J. T. (2010). Gestão ambiental de áreas degradadas. Rio de janeiro: Bertrand Brasil.

Boff, L. (2015). Sustentabilidade: O que é - o que não é. 4 ed. Petrópolis, Rio de Janeiro: Vozes.

Costa, A.J.V. (2010). A Relevância do Pensamento Agroecossistêmico de Josué de Castro para a reflexão agroecológica no Brasil: Potencialidades de uma abordagem histórico-ambiental. (Tese) Programa de Pós-Graduação em Sistemas de Produção Agrícola Familiar. Universidade Federal de Pelotas. Pelotas.

Cruz, J.S.; Souza, C. A.; William, C. S.; Silva, V. N. (2017). O Uso da Terra e dos Recursos Hídricos da Bacia do córrego Facão, Pantanal de Cáceres, Mato Grosso. DOI - 10.20396/sbgfa.v1i2017.1773 ISBN 978-85-85369-16-3.

Galvão, P.; Mendes, A.; Sousa, J.; Silva, I.; Carneiro, R. (2019). Relações entre qualidade da água subterrânea e ocupação desordenada em um bairro be baixa renda localizado em uma antiga área de lixão, Santarém/PA. XX Congresso Brasileiro de Águas Subterrâneas.

Guerra, A.; Fullen, M.; Jorge, M.; Alexandre, S. (2014). Soil Erosion and Conservation in Brazil. Anuário do Instituto de Geociências, v.37, p.81-91.

Metring, R.A. (2009). Pesquisa Cientifica: Planejamento para iniciantes. Curitiba: juruá Editora.

Nunes, J. F.; Roig, H. L. (2015). Análise e mapeamento do uso e ocupação do solo da bacia do alto do descoberto, DF/GO, por meio de classificação automática baseada em regras e lógica nebulosa1. Revista Árvore, Viçosa-MG, v.39, n.1, p.25-36.

Perazzoli, M.; Pinheiro, A.; Kaufmann, V. (2013). Efeitos de Cenários de Uso do Solo sobre o regime Hídrico e Produção de sedimentos na Bacia do Ribeirão Concórdia - SC. Revista Árvore, ViçosaMG, v.37, n.5, p.859-869.

Pinheiro, A.; Bertoldi, j.; Vibrans, A. C.; Kaufmann, V. Deshayes, M. (2011). Uso do Solo na zona ripária de bacias agrícolas de pequeno a médio porte. Revista Árvore, v.35, n.6, p. 1245- 1251. 
Pereira, M.A.S.; Magalhães Filho, F.J.C.; Teles, A.P.S.; Ayres, F.M. (2019). Caracterização Ambiental do uso e ocupação do solo das áreas de influência em municípios da rota de Integração Latino-Americana. Interações, Campo Grande, MS, v. 20 , n. 2 , p. $255-266$,

Primavesi, A. (2014). Pergunte ao solo e às raízes: uma analise do solo tropical e mais 70 casos pela agroecologia. 1 ed. São Paulo: Nobel.

Pruski, F. F., Lineu N. Demetrius D. S. (2001). Modelo hidrológico para estimativa Modelo hidrológico para estimativa do escoamento superficial em áreas agrícolas Revista Brasileira de Engenharia Agrícola e Ambiental, v.5, n.2, p.301307.

Ribeiro, B. M. G.; Fonseca, L. M. G.; Kux, H. J. H. (2011). Mapeamento da cobertura do solo urbano utilizando imagens WorldView-II e o Sistema Interimage. Revista Brasileira de Cartografia, v. 63, Edição Especial 40 Anos. pp. 51-63.

Rother, E.T. (2007). Revisão sistemática X revisão narrativa. Revista Acta Paulista de Enfermagem. São Paulo. V.20, n2, p. 4 -5.

Santana, A.L.S; Araújo G. L. (2017). Erosão do solo em uma propriedade rural no município de Abre Campo (MG). III Seminário Científico da FACIG / II Jornada de Iniciação Científica da FACIG.

Santos, M. (2005). A urbanização brasileira. São Paulo: EDUSP.

Santos, P. S. (2019). Estimativa de escoamento superficial na bacia hidrográfica do rio una,
Taubaté - SP. (Dissertação). Programa de PósGraduação em Ciências Ambientais da Universidade de Taubaté.

Santos, E. R.; Leite, C. R. S.; Perim, M. A.; Gonçalves, S. F.; Targa, M.S. (2020a). Urbanização Sustentável e o Escoamento em Bacias Hidrográfica. UNITAU, (2016) Ver Ciências Ambientais.

Santos, P. S; Targa, M.S; Santos Junior, P. S. (2020b) Uma Discussão Reflexiva sobre o impacto recorrente de infiltração nos rios, resultante da má utilização do uso do solo pelo homem. Anais do SERENS: Seminário sobre Energias Renováveis, Eficiência Energética e Sustentabilidade. IFBA Campus Camaçari.

Sartori, A. A. C.; Barbosa, A. P.; Pisani, R. J.; Oliveira, F.G.; Zimback, C. R. L. (2009) Mapeamento de conflitos de solo em área de preservação permanente na Bacia Experimental do Rio Pardo. São Paulo. In: Simpósio Brasileiro de Sensoriamento Remoto. Natal. Anais INPE, P. $6197-$ 6202

Silva P.J. (2015). Uso e Ocupação do Solo Urbano: Uma análise dos impactos ambientais nas áreas de dunas no bairro de Felipe Camarão/Natal-RN. Universidade Federal do Rio Grande do Norte. Holos, Ano 31, Vol. 5 UFRN.

Targa, M.S. (2011). Vazão de projeto em bacias hidrográficas rurais com áreas em declive. Repositório Eletrônico Ciências Agrarias. UNITAU/Taubaté. Programa Pós-Graduação. 